ities. An article on the subject by Harold Moyer appeared in the "Alienist and Neurologist," January, I890, in which the author suggests that in these days of germs and ptomaines, the theory of auto-infection will be more acceptable to many. Whether as an irritation beginning in the peripheral endings of the sympathetic nerves, propogated to the vaso-motor supply of the central nervous system and there working disorder principally in the circulation, or as an addition to the blood of noxious elements that produce toxic effects, the disorder manifests itself by an intellectual disturbance, characterized by a peculiar depression of spirit, by anguish of mind, and by the patient's self-accusations of wickedness and baseness. The disease has a very slow course and generally this anguish has existed some time before a physician is consulted. Van der Kolk was himself a sufferer, to the degree of hallucinations and phantasms that appeared for three days. Copious enemata that removed enormous quantities of fecal matter cured him; and Dr. Moyer's patients - three cases of typical insanitywere restored by similar measures. Drastics only increase the tendency to stricture. They add to the sensibility of the colpn and the accumulation of blood in it, and cause watery stools, while the hard masses in the upper portion of the large intestine still remain. Disquietude and excitement increased, the strength diminished, and the circulation made more irregular by this treatment. Where there is a true over-filling of the bowels, with distension of the pouches of the colon, drastics and cathartics are of little use.

FXCERPTS FROM GERMAN AND FRENCH JOURNALS.

By Drg. F. H. PRITChaRd AND ALBERT PICK (Boston).

SCOLIOSES IN SCIATIC NEURALGIAS.

E. Brissaud (Arch. de Neurol., I890, Vol. I9, No. 55). The deviations of the trunk in sciatica have recently been studied by Charcot, Ballet and Babinsky. There is in many cases of sciatica, according to Babinsky, a more or less pronounced inclination of the vertebral column towards the unaffected side of the body; this symptom is overlooked by many investigators, as it is not especially sought for. The costo-iliac interspace gives one a measurement of the spinal deviation. The shoulder in question is also not always inclined towards the unaffected side, this being prevented by compensatory movements of the spine above the dorso- 
lumbar curve, and indeed with over-compensation the shoulder of the unaffected side may be higher than that of the affected side. The head of the patient may be straight, or according to the compensatory curve, it may incline towards one or the other. In diagnosticating, one should distinguish between a scoliosis independent of sciatica, a chronic rheumatic process of the sacro-vertebral joints, and hysteric coxalgia.

The cause of the deviation described is muscular, and indeed a simple contraction of the muscles of the unaffected side, resulting from the patient trying to throw the weight of the body upon the sound leg. The leg of the unsound side is easily flexed, and the sole of the foot rests with its entire surface upon the ground.

One sees an example of a professional muscle spasm in the inclination of the shoulder towards the left in violinists.

The atrophy of the muscles on the affected side not rarely extends outside of the region of the ischiadic nerve.

B. then cites three cases in which exceptionally the body was inclined towards the affected side. These cases were spastic, the curvature being caused by a contracture of the muscles, while the "scoliose croisee" is only based upon a contracture of the muscles. Not rarely there is a increase of the tendo-reflexes, which, however, may be seen in every painful affection of the lower extremities. Not rarely. the "ischiasis" is not a neuralgia in the region of the sciactic nerve, but of the lumbo-sacral plexus; from these various contractions and contractures of the loin- and legmuscles the different deviations in the position of the legs and body originate.

\section{ON THE NERVOUS FORMS OF THE GRIPPE.}

Prof. L. Revilliod (Rev. médic. de la Suisse Romande, I890, No. 3). R. gives an interesting contribution to the knowledge of the nervous forms of the grippe, adding it to several cases chosen from those under his observation. The most prominent place is given to delirium, which he also most fully describes.

The intensity of the delirium stands in a misrelation to the objective symptoms which often are scarcely remarked. It nearly always accompanies the pneumonia of influenza, but, however, is to be closely distinguished from the usual pneumonia delirium, for in pneumonia the delirium sets in at the stadium acmes, and in fatal cases persists until death; but in the grippe it is often the harbinger of pneumonia, or it may appear in the stadium decrementi and last 